\section{Máquinas e argumentos: das tecnologias de suporte da vida à definição de morte cerebral*}

\section{Machines and arguments: from life support technologies to the definition of brain death}

KIND, Luciana. Máquinas e argumentos: das tecnologias de suporte da vida à definição de morte cerebral. História, Ciências, Saúde - Manguinhos, Rio de Janeiro, v.16, n.1, jan.-mar. 2009, p.13-34.

\section{Resumo}

Analisa a produção acadêmica sobre $o$ debate em torno da definição da morte cerebral concentrado na década de 1960 e publicado em periódicos médicos de destaque internacional. Enfatiza que tecnologias de suporte de vida desenvolvidas ao longo do século $\mathrm{XX}$ e incorporadas na cena médica provocaram intenso debate em busca de legitimidade para novos procedimentos, como os transplantes de órgãos. Com suas práticas modificadas, a ciência médica pôs-se a inventar novos conhecimentos a esse respeito. As discussões sobre a definição de morte cerebral acabaram por transformá-la numa caixa-preta, que viria a ser desmontada pelos estudos antropológicos sobre o assunto desenvolvidos a partir dos anos 80 . Este trabalho, por meio de suas análises, também se compromete com a desconstrução da morte cerebral como caixa-preta.

Palavras-chave: história da medicina, tecnologias de suporte de vida, definição de morte cerebral.

Abstract

The article analyzes academic production about the debate surrounding the definition of brain death, based on bibliographic and documental research of international medical periodicals in the 1960s. The development and adoption of life support technologies during the twentieth century sparked a heated debate that sought to legitimize new procedures like organ transplants. As its practices changed, medical science set about inventing new knowledge about these practices. Discussions as to the definition of brain death turned it into a 'black box', dismantled by anthropological studies into the topic starting in 1980s. The present article explores the deconstruction of brain death as a black box.

Keywords: history of medicine; life support technologies; definition of brain death. 
- Prepare-se para ouvir o relato de acontecimentos que normalmente poderiam ser considerados fantásticos ... . Muitas coisas são possíveis nessas regiões misteriosas; coisas que poderiam provocar o riso dos poucos afeitos às forças mutáveis e inelutáveis da natureza.

Mary Shelley; fala de Victor Frankenstein

A história da redefinição da morte protagonizada em meados no século XX apresenta-se como composição em que, muitas vezes, as máquinas e práticas se anteciparam aos argumentos. Edificadas no pantanoso terreno da fronteira entre a vida e a morte, as práticas médicas que tornaram possíveis os transplantes de órgãos obrigaram a ciência a se justificar. Essas tecnologias reforçaram a construção de uma morte moderna, medicalizada, ligada a aparelhos, produtora de cadáveres funcionais.

À medida que a experimentação em seres humanos foi incrementada com o uso de maquinário e técnicas cada vez mais sofisticadas, o diálogo entre a medicina e outros campos de conhecimento tornou-se imperativo. O debate ganhou contornos filosóficos em publicações médicas, para dar conta da necessária redescrição do que é o ser humano, em especial aquele que morria ligado a aparelhos em meados do século passado, mas que emergia como possibilidade de garantir à biomedicina a invenção de procedimentos outrora não permitidos.

Este texto dedica-se ao estudo da mobilização de alguns campos de conhecimento em torno de questões apropriadas pela medicina devido ao crescente uso de máquinas e inovações tecnológicas no fazer médico, tendo como ponto culminante o movimento de redefinição da morte no final da década de 1960 . Tem-se por objetivo analisar os relatos sobre o desenvolvimento de tecnologias de suporte de vida que demandaram uma redefinição de morte e tornaram possível o transplante de órgãos. Destaco, da literatura médica de meados do século passado, debates e atores importantes para a construção e consolidação de uma nova definição de morte. São analisados, nesse cenário, a proliferação de máquinas e procedimentos médicos que antecederam a construção de argumentos para sustentá-los e a rede de saberes concorrentes que se vai formando em torno das tecnologias médicas que criaram as condições de possibilidade para a definição de morte cerebral.

Da literatura médica e publicações afins destacam-se alguns pressupostos e atores que se dedicaram a transformar a morte cerebral numa caixa-preta, em consonância com Latour (2000). A noção de caixa-preta utilizada pelo autor tem seu significado emprestado da cibernética, descrevendo-a como "máquina ou conjunto de comandos" que se revelam complexos demais. Latour propõe uma "entrada no mundo da ciência e da tecnologia" pela porta de trás, a da ciência em construção; propõe que nos posicionemos antes de a caixa-preta se fechar e adquirir a dimensão de verdade científica. Para isso, sugere que sigamos o melhor dos guias: os próprios cientistas, "em sua tentativa de fechar a caixapreta". Propõe então a decomposição de uma caixa-preta a partir das publicações ou do que nomeia como a "anatomia dos textos científicos".

Pretendo portanto, neste artigo, acompanhar a história da definição de morte cerebral, que se desenrola no século XX, identificando práticas, argumentos e atores que a compõem. O foco da análise está nas publicações acadêmicas, meios de divulgação por excelência das 
idéias e dos argumentos que se pretendem 'fatos' ou 'verdades' científicas. O que interessa a esta discussão são os documentos científicos que defendem a redefinição da morte em decorrência dos avanços tecnológicos desenvolvidos na medicina no século passado.

Observa-se que do século XX em diante a medicina, com suas novas tecnologias, tem produzido mudanças radicais nos modos de morrer. A morte assistida, acompanhada por uma variedade de tubos, aparelhos, profissionais de saúde e medicamentos, tem sido o padrão 'americanizado' e internacional (Vovelle, 1983). Intimamente ligadas a esse novo cenário de morte estão as tecnologias médicas que levaram ao transplante de órgãos. Nesse contexto, o desenvolvimento dos respiradores artificiais e das unidades de terapia intensiva foi crucial para que o transplante de órgãos ganhasse viabilidade. Pretende-se apontar que o passo a passo da incorporação dessas tecnologias ao cotidiano dos procedimentos médicos foi acompanhado pelo desenvolvimento de concepções biológicas, filosóficas e jurídicas sobre o ser humano e por diversificado debate ético em que se rededesenhou o que é morte e o que é vida.

\section{Tecnologia em cena, práticas médicas modificadas}

A tecnologia médica, pensada em seu entrelaçamento com a vida pública, exerceu diferentes ações sobre problemas sociais distintos, mas pôde ser incorporada em práticas e procedimentos gerando novos problemas e novas tecnologias para lidar com eles. Exemplo notável é o respirador artificial, dispositivo criado para tratar epidemias de poliomielite nos Estados Unidos e na Europa e que, posteriormente, tornou-se essencial para o avanço das unidades de tratamento intensivo. O efeito mais direto da incorporação de novas tecnologias na prática médica é a necessidade de recriar conhecimentos e aparatos que vão sendo rapidamente entendidos como obsoletos.

A partir da década de 1920, os hospitais se tornaram espaços de aplicação científica (Howell, 1995). A observação clínica foi potencializada pelo conhecimento científico e pelas máquinas. Nesse contexto, intricada por políticas financeiras também modificadas, a tecnologia apresentava três níveis distintos: a máquina, a prática e o know-how. Vistos e divulgados como símbolos do progresso, as práticas e os aparelhos tecnológicos eram (e ainda são) anunciados como imprescindíveis para a melhoria da vida cotidiana.

Defensor do avanço tecnológico, Thomas (1971) demarca três diferentes tipos de tecnologia médica, discriminados pela relação custo/benefício. O primeiro tipo não envolveria maquinário, sendo por isso nomeado 'não-tecnologia'. Caracterizada pelo conjunto de cuidados envolvido na terapia intensiva e paliativa, essa não-tecnologia contaria principalmente com recursos humanos, tornando o tratamento altamente oneroso. $\mathrm{O}$ segundo tipo é atacado pelo autor, que considera essas 'tecnologias incompletas' (halfway tecnhnology) "altamente sofisticadas e profundamente primitivas"1 (p.1367). Como exemplo desse segundo tipo, o autor aponta o iron lung, pulmão de aço desenvolvido por Drinker e Shaw (1932) para o tratamento da poliomielite. Com altos custos de fabricação e operacional, esse tipo de tecnologia deve ser transitório, passível de ser superado. O terceiro tipo diria respeito às 'tecnologias genuínas' da medicina moderna, as de baixo custo e alta eficácia, como por exemplo as vacinas. Toda tecnologia deveria então chegar ao patamar 
deste último tipo ou seria inviável para a prática cotidiana. Tal perspectiva é fortemente criticada por Maxwell (1986), que, como contraponto, apresenta a história do desenvolvimento dos iron lungs e recupera a importância desse aparato para novas descobertas médicas. Acompanharemos um pouco dessa história e seus desdobramentos.

Diante do surto de poliomielite que acometeu os Estados Unidos no início do século XX, médicos do Hospital Infantil de Boston convidaram o engenheiro Phillip Drinker para projetar um respirador artificial que auxiliasse na assistência às vítimas da epidemia. Com Louis Shaw, seu colaborador da Universidade de Harvard, Drinker desenhou e testou em animais o protótipo do iron lung, utilizando-o primeiro em gatos.

$\mathrm{O}$ aparelho, que consistia numa câmara de ar de pressão negativa com um mecanismo elétrico, mostrou-se eficaz em animais e rapidamente foi incorporado à cena hospitalar (Drinker, Shaw, 1932; Maxwell, 1986). O paciente, passivamente colocado nessa câmara, era forçado a respirar, o que aumentava suas possibilidades de sobrevivência. Muitos aparelhos similares ao desenhado por Drinker foram desenvolvidos posteriormente, mas nenhum deles se mostrou eficiente para o tratamento do tipo específico de pólio que se alastrou no início dos anos 50 .

Em Copenhague, Dinamarca, o surto de pólio bulbar foi devastador, obrigando os hospitais a procurar todo o auxílio especializado. Lassen e Ibsen, dois médicos dinamarqueses, ficaram conhecidos pelo uso de métodos extraordinários que inovaram a tecnologia de respiração artificial conhecida até então. Lassen (1956) pondera que identificou no Hospital Blegdam, em 1952, um imperativo para o improviso.

Na década de 1970, celebrando o 25o aniversário do campo da anestesiologia, Ibsen (1975) publicou suas memórias pessoais no suplemento da Acta Anaesthesiologica Scandinavica. Junto a uma série de auto-elogios, ele apresenta alguns tópicos interessantes sobre sua trajetória como testemunha e importante ator do desenvolvimento de determinadas tecnologias médicas. Em 1949 ele passou um ano no Hospital Geral de Massachusetts, Estados Unidos, tendo Henry Beecher como preceptor. Beecher viria a publicar, com alguns colaboradores, o notório A definition of irreversible coma, relatório do Ad Hoc Commitee of the Harvard Medical School, um coletivo organizado em torno da tarefa de examinar a definição de morte cerebral (brain death). ${ }^{2}$ Ibsen revela em suas memórias o espírito de "livre troca de idéias" em que se produzia pesquisa junto ao grupo de Beecher. Outro ponto importante em seu relato é a emergência da anestesiologia como especialidade independente da cirurgia. O 'improviso' de 1952 rendeu-lhe fama, além de espaço profissional, e ao final de 1953 ele contava com uma sala de recuperação com dez leitos em funcionamento permanente, unidade da qual posteriormente se tornou chefe. A terapia intensiva é apresentada por Ibsen como devedora dos avanços da anestesiologia.

Por cerca de duas décadas a respiração artificial esteve a serviço da poliomielite. Sua validade para esse tratamento expirou com as vacinas de Salk e Sabin. Tecnologia simples, comparada com os respiradores artificiais, e voltada diretamente para a doença, as vacinas de Salk (1953) e Sabin (1956) reduziram drasticamente a incidência da pólio (Katz, 2004). Contudo as memórias de Ibsen nos dão uma idéia da tendência de utilização da tecnologia anterior no tratamento da doença. Longe de tornar-se obsoleta, ela foi deslocada para os cuidados intensivos, área em que ganhou vida longa e prometeu dar o mesmo aos pacientes. 
Apesar de descritas já no final do século XIX, as salas de recuperação assumiram contornos de unidades de terapia intensiva com os avanços na respiração artificial. Na Segunda Guerra Mundial, unidades de terapia intensiva foram desenvolvidas para atender os soldados feridos. Gradativamente, com produção de conhecimento na anestesiologia e na cirurgia, tornaram-se imprescindíveis nos hospitais. Técnicas de ressuscitação foram sendo incorporadas aos cuidados intensivos. As antigas salas de recuperação eram descritas como lugares tranqüilos, em que pacientes gravemente doentes esperavam o restabelecimento da saúde. Gradualmente transformaram-se em agitados espaços em que circulavam enfermeiros, anestesistas, cirurgiões e outros especialistas, a fazer prescrições e administrar drogas miraculosas e dependendo de aparelhos cada vez mais sofisticados, que imprimiam no ambiente seu ruído constante (Hilberman, 1975; Bendixen, Kinney, 1977).

O desenvolvimento das unidades de terapia intensiva consolidou a subdivisão de tarefas e responsabilidades entre diversas especialidades médicas e profissionais de enfermagem. Essas unidades também favoreceram o desenvolvimento de novos conhecimentos sobre administração de cuidados, bem como o surgimento de novas drogas. Apesar do entusiasmo inicial, o imperativo de ressuscitar o paciente e conectá-lo a um respirador artificial apresentou uma nova figura humana: corpos com vida, literalmente conectados ao mundo por fios. Animados pelo lema do 'dever de salvar vidas', mas divididos quanto ao que fazer com os ditos casos sem esperança, os médicos deparavam com problemas morais apresentados por aqueles corpos que respiravam artificialmente mas não tinham perspectiva de resgatar condições aceitáveis de saúde. Stevens (1995) chama a atenção para os problemas criados pelas tecnologias de suporte da vida, que considera não apenas médicos mas também teológicos, sociais e legais, o que provoca ansiedade moral. O triunfo dos aparatos para prolongar a vida esmorecia diante de um efeito indesejado: prolongar o morrer.

Os dilemas morais identificados pela comunidade de anestesiologia foram encaminhados à Igreja católica, ou melhor, a seu representante maior, o papa. Em 1957 Pio XII endereçou um discurso, conhecido como "The Prolongation of Life", para o Congresso Internacional de Anestesiologia. Três questões haviam sido levantadas para a Igreja. A primeira ponderava sobre o direito ou a obrigação do recurso a tecnologias de reanimação em todos os casos, mesmo naqueles em que os especialistas não tinham esperança de sobrevivência. A segunda refletia sobre a tarefa ou obrigação médica de retirar os aparelhos quando se constatasse a parada circulatória em pacientes em estado de inconsciência profunda; e se, nesses casos, a extrema-unção seria válida antes da retirada dos aparelhos. Por fim, embora não menos importante, perguntava-se: os pacientes em estado de inconsciência, paralisia total e com a circulação sanguínea mantida por suporte artificial estariam mortos de facto ou de iure?

Pio XII respondeu uma a uma às questões levantadas. Em seu discurso, lembrava que é dever do cristão cuidar de seu semelhante tendo por princípio a manutenção da vida e da saúde. No entanto os meios ordinários disponíveis deveriam ser priorizados, especialmente na anestesiologia. Afirmava que só a família poderia insistir em desligar os aparelhos, caso não houvesse esperança de recuperação da consciência; à medicina caberia, nesses casos, obedecer. Respondeu afirmativamente à questão relativa ao desligamento dos aparelhos, pelos médicos, em casos de parada respiratória. Quanto à extrema-unção, porém, 
questionava se pode haver, nessas situações, um ser humano em condições de receber o sacramento. A terceira pergunta, entretanto, foi devolvida, encaminhada à comunidade médica para esclarecimentos sobre os produtos subumanos de suas novas tecnologias:

\begin{abstract}
Compete ao médico, em particular ao anestesiologista, produzir uma definição clara e precisa da 'morte' e do 'momento da morte' de um paciente que falece em estado inconsciente. Por isso, pode-se retomar o conceito usual de separação completa e definitiva da alma e dos corpos; mas, na prática, deve-se levar em consideração a imprecisão dos termos 'corpos' e 'separação'. Pode-se desconsiderar a possibilidade de um homem ser enterrado vivo, visto que a retirada do aparelho respiratório, após alguns minutos, provoca a parada da circulação e, portanto, a morte (Pio XII, nov. 1957, p.1031).
\end{abstract}

A tarefa de redefinir a morte era imprescindível. O próprio pontífice antecipava que a "definição clara e precisa" era uma alternativa àquela em vigência, ou seja, a morte por parada cardiorrespiratória. Demandava-se uma segunda definição, relacionada à ausência de consciência do paciente. Frank Ayd (1962) descreve a situação corrente dos casos sem esperança e critica o movimento de seus colegas médicos em direção a 'tratamentos heróicos' para salvar vidas. Referindo-se precisamente aos aparelhos de suporte da vida, ele afirma que diante da morte iminente não é "nem científico, nem humano procrastinar a vida de um paciente" (p.1102). Para sustentar seu argumento, o médico se apóia numa carta anônima, mas atribuída a uma viúva que perdera seu marido cercado da fausta tecnologia de suporte da vida. O relato tem como personagens um paciente recém-saído de uma cirurgia e sua acompanhante. Após testemunhar a rotina hospitalar, os procedimentos invasivos, a obrigatoriedade de se fazer tudo que estava ao alcance da tecnologia vigente, culminando com o coma e a morte do paciente, a acompanhante alerta os despreparados: "Há uma nova maneira de se morrer nos dias de hoje. É o percurso lento pela medicina moderna. Se você está muito doente a medicina moderna pode te salvar. Se você está morrendo ela pode te impedir de fazer isso por um longo período ... . Para aqueles que acompanham e assistem, isso parece uma imposição terrível contra a vontade de Deus (Anônimo, Jan. 1957, p.53).

As questões morais debatidas por médicos e teólogos levantavam as responsabilidades a serem assumidas ao se optar por meios extraordinários para prolongamento da vida: desligar ou não desligar aparelhos? quem deveria autorizar ou fazer isso? quando fazê-lo? A esse respeito, algumas posições ambíguas podem ser encontradas em Laforet (Sep. 1963), Williamson $(1966,1967)$ e Reid (1967), que interrogam os médicos sobre seu papel de se responsabilizar pelos chamados 'pacientes sem esperança' (hopeless patients). Ao concluir sua conferência no $10^{\circ}$ Congresso Internacional de Médicos Católicos, Laforet (Sep. 1963) rechaça essa expressão, sustentada por médicos para nomear os pacientes que ele considerava vítimas da tecnologia médica. Essa vertente do debate insistia em afirmar que as tecnologias de prolongamento da vida tinham instaurado, em contrapartida, o 'prolongamento do morrer'. Mas a defesa das tecnologias empregadas àquela época também tinha espaço no debate. Farrell (1958) sustenta que a medicina trouxe à tona descobertas estarrecedoras e que, portanto, a ignorância com relação às descobertas mais recentes não poderia ser tolerada na era moderna.

Àquela época o transplante de órgãos já estava em pauta. O primeiro transplante renal entre doadores vivos fora realizado em 1954. Atender à prescrição do papa Pio XII parecia 
ser a mais sensata das tarefas. Fomentavam o debate corpos conectados a máquinas, híbridos produzidos pela tecnologia, mas sem ação, em estado vegetativo, matéria-prima essencial para a crescente demanda de órgãos humanos.

\section{A redefinição da morte nos anos 60}

Na década de 1960 as publicações começam a tomar nova forma, pois autores isolados passaram a compor grupos, comissões e instituições organizados por interesses específicos no debate sobre a redefinição da morte. $\mathrm{O}$ formato de comissão foi adotado nas principais publicações sobre o assunto, por salvaguardar autores do constrangimento de emitir suas opiniões individuais sobre questão tão delicada. Foram criados grupos com posições opostas e pontos de convergência no debate, o que promoveu ampla publicação de artigos nos periódicos médicos e de áreas diretamente envolvidas nessa primeira onda de discussões, como filosofia, teologia e direito. Assim, a produção de textos em cadeia, observada no debate sobre a redefinição da morte, teve como força emergente coletivos nitidamente empenhados em elevar a recém-definida morte cerebral ao nível de fato científico.

Leslie Rado (Winter 1987) sustenta que o estabelecimento de uma 'elite multidisciplinar' caracterizou o movimento de redefinição da morte. Aponta duas motivações cruciais para a emergência dessa elite, ambas associadas à moderna prática médica: a primeira teria sido gerada pelo alto custo financeiro e emocional do prolongamento da vida; a segunda, pela necessidade crescente de obtenção de órgãos para transplantes.

A antropóloga analisa a trajetória dos membros dessa elite em termos biográficos, geográficos e institucionais e destaca as suas contribuições para a institucionalização do conceito de morte cerebral. Os representantes dessa elite tinham trajetórias intelectuais e ocupações institucionais, diversificadas, e um conjunto de médicos, teólogos e juristas conceituou, redefiniu e legitimou uma nova noção de morte. No campo jurídico, por exemplo, argumentava-se que a redefinição do termo, ocorrida nos anos 60 e 70, era reclamada desde a década de 1950.

Vinte e seis homens foram listados por Rado (Winter 1987) como componentes dessa elite. Deles, apenas seis não ocupavam posições acadêmicas nem eram professores universitários, e nove desenvolviam pesquisas financiadas ou eram chefes de seus departamentos ou laboratórios. Quatorze estavam vinculados a universidades proeminentes no cenário nacional e internacional - um deles, o médico Gunnar Biork, era conselheiro de Saúde da Suécia. Outros ocupavam postos editoriais em periódicos científicos. Todos eram respeitados profissionais em suas respectivas áreas. Em sua maioria eram médicos (46\%), seguidos por alguns dos precursores da bioética (31\%) e por advogados (23\%).

Entre os elementos que Leslie Rado (Winter 1987) aponta, a respeito do debate sobre a redefinição da morte e a expansão do campo de transplante de órgãos, consta o papel marcante de duas publicações veiculadas pelo Journal of the American Medical Association (Jama): o relatório do Ad Hoc Commitee of Harvard Medical School (Aug. 1968) e o Uniform Determination of Death Act (President's Commission..., Nov. 1981).

No intuito de identificar pontos da discussão em torno da morte cerebral e do transplante de órgãos, realizei uma busca nos números do Jama publicados em 1967, 1968, 1969 e 1981. 
Incluí o ano que precedeu e o que sucedeu o relatório do Ad Hoc Committee, porque este é considerado, em toda a literatura consultada, marco da discussão do assunto. Quanto ao ano de 1981, nele foram publicados dois importantes documentos de outro coletivo, a President's Commission for the Study of Ethical Problems in Medicine and Biomedical and Behavioral Research. Os documentos publicados naquele ano foram o relatório sobre a redefinição da morte, intitulado "Defining death" (President's Commission..., 1981) e o já mencionado Uniform Determination of Death Act (UDDA). Essas publicações foram citadas por várias "gerações de textos" (Latour, 2000), em artigos acadêmicos diversos. Desde o período em que foram publicadas até os dias mais contemporâneos elas são citadas pelos adeptos da definição de morte cerebral em sua formulação original ou, com raras exceções, com pequenas modificações visando atualizá-las. Esse processo de reafirmações múltiplas e persistentes, com muitos opositores, mas também com muitos simpatizantes e partidários, transformou a morte cerebral em caixa-preta. O Jama constitui um dos mais notáveis veículos de defesa da definição.

Em sintonia com o pensamento de Fleck (1979), pondero que, uma vez publicada, a definição de morte cerebral se propagou como força social, desdobrando-se em novas definições e conceitos que criaram, por sua vez, "hábitos de pensamento" (p.37). Ao refletir sobre a morte no contexto das práticas médicas a partir do final dos anos 60 , nem leigos nem especialistas se poderiam esquivar da definição de morte cerebral. Nesse cenário de publicações, outros dois periódicos, o Hastings Center Report e o New England Journal of Medicine, mostraram-se importantes canais de divulgação de posições favoráveis e contrárias à definição de morte cerebral. Dos anos subseqüentes a 1968 até a atualidade, essas revistas fomentaram debates importantes, revelando a ausência de consensos e a proliferação de controvérsias. Artigos isolados, especialmente aqueles cujos autores são apontados como importantes defensores da definição de morte cerebral, serão também abordados.

Das publicações do Jama destacam-se três textos de suma importância para esse cenário: (1) "A definition of irreversible coma" (Ad Hoc Committee..., Aug. 1968); (2) Uniform Anatomical Gift Act (National Conference..., Dec. 1968), aprovado em julho de 1968, mas publicado em dezembro daquele ano; e (3) "Guidelines for the determination of death" (President's Commission..., Nov. 1981). Os três são relatórios e têm como autores comissões interdisciplinares. O primeiro ficou conhecido como a publicação seminal da definição de morte cerebral. Atacado por muitos, apresentava seu objetivo e duas justificativas para que se delimitasse uma nova definição de morte:

Nosso objetivo principal é definir o coma irreversível como um novo critério para a morte. Há duas razões pelas quais essa definição é necessária: (1) Avanços nas medidas de ressuscitação e de suporte [da vida] têm levado ao aumento de esforços para salvar aqueles que estão drasticamente enfermos ... (2) Critérios obsoletos para a definição da morte podem levar a controvérsia na obtenção de órgãos para transplante (Ad Hoc Committee..., Aug. 1968).

Em vez de evitar controvérsia, o relatório do Ad Hoc Committee concentrou-se nas críticas acerca da nova definição, morte cerebral, ao mesmo tempo que iniciou sua legitimação. Não apenas nos Estados Unidos, mas também em vários países onde cirurgias de transplantes estavam acontecendo, novos critérios para além daqueles definidos pelo documento começaram a ser forjados. O relatório, por si só, parece ter legitimado a 
experimentação médica e o debate irrestrito em torno da definição de morte cerebral; mas tornar tal definição aceitável, algo em que se acreditasse, ainda estava por se fazer mediante políticas públicas específicas, que teriam o papel de institucionalizar a nova definição. $\mathrm{O}$ relatório é obviamente endereçado à comunidade médica, com o evidente objetivo de redefinir a concepção vigente de morte, o que pode ser verificado em alguns aspectos da publicação: a autoria coletiva liderada por Beecher; a veiculação no periódico da American Medical Association; e o título, no qual aparece a expressão 'coma irreversível', com seu equivalente, brain death, explicitado no subtítulo.

Durante aproximadamente uma década depois dessa publicação, muitas críticas e muitas adesões à nova definição de morte ganharam força. Aliado da redefinição da morte, o debate sobre experimentação envolvendo sujeitos humanos é publicado em edição temática do periódico da Academia Americana de Artes e Ciências (Daedalus, Spring 1969). Nessa edição, dois artigos se destacam por trazer um debate mais objetivo sobre a então recémdefinida morte cerebral. O primeiro, assinado por Hans Jonas, um dos atores da elite cultural identificada por Rado (Winter 1987), critica a intenção explícita da nova definição de morte em prover o carente campo dos transplantes.

Quando se trata de uma mera questão de quando é permitido interromper o prolongamento artificial de certas funções (como o batimento cardíaco) tradicionalmente identificadas como sinais de vida, não vejo nada de nefasto na noção de 'morte cerebral' ... . Mas um objetivo inquietantemente contraditório se combina ao propósito da busca de nova definição da morte: a permissão não de desligar o respirador [artificial] mas, ao contrário, de mantê-lo ligado e, dessa forma, manter o corpo num estado do que teria sido a 'vida', na velha definição (mas que é apenas um 'simulacro' de vida, na nova) - de maneira a conseguir os órgãos e tecidos em condições ideais, o que poderia ser previamente visto como vivisseção (Jonas, Spring 1969, p.244).

O segundo artigo é de Beecher que, ao contrário de Jonas, defende abertamente a servidão da morte cerebral aos transplantes de órgãos, tese apresentada de maneira mais comedida no relatório do Ad Hoc Committee.

No campo do transplante de órgãos há duas grandes barreiras para o progresso: o fenômeno da rejeição imunológica e a grande escassez de material para doação. Até o momento o fenômeno da rejeição está, de todas as maneiras, além do nosso controle, mas está ao alcance do nosso poder dar um grande passo à frente em atenuar a escassez de material para doação. Esse desejo requer cooperação prioritária daqueles envolvidos, a concordância da sociedade e, finalmente, a aprovação da legislação. O ponto crucial é a concordância de que a morte cerebral é de fato a morte, ainda que o coração continue a pulsar (Beecher, Spring 1969, p.291; grifo meu).

Nessa defesa sem meias palavras, Beecher equipara a morte cerebral à morte, ponto polêmico do debate. A publicação da Daedalus inaugura o movimento - que acompanha os desdobramentos da redefinição da morte - de publicar coletâneas com distintos posicionamentos acerca do assunto. Tais publicações refletem o clima tenso do lento e burocrático processo de definição de morte cerebral, de maneira a beneficiar o campo emergente dos transplantes de órgãos. Os artigos favoráveis e contrários à definição, bastante numerosos nas coletâneas, adicionam-se àqueles publicados em periódicos, contribuindo 
para dar autoridade aos argumentos e aparência de um debate democrático e amplo sobre a questão. Dentre essas publicações destacam-se os livros editados por Zaner (1988) e Youngner, Arnold e Schapiro (1999), copiosamente citados em publicações posteriores. Além desse tipo de compilação de artigos de diferentes autores com posições divergentes sobre a morte cerebral, muitos autores proeminentes nesse contexto expuseram em detalhes seus argumentos, em livros próprios (Ramsey, 1970; Veatch, 1976).

Contudo a experimentação médica e sua interface com o campo jurídico ofereceram nesse período construções díspares de procedimentos para o diagnóstico de morte cerebral. Analisando essa interface entre o saber médico e sua institucionalização, Lock (2002) descreve o processo que levou os Estados Unidos a buscar consenso técnico para o diagnóstico de morte cerebral, o que demonstra o reconhecimento da necessidade de serem estabelecidas políticas públicas consistentes relativas à redefinição da morte.

Um texto de 1978 no New England Journal of Medicine avaliava as conseqüências da ausência de uniformidade nos critérios diagnósticos para morte cerebral. Black (1978), num artigo publicado em duas partes, acentuava os perigos da ausência de consenso quanto a esses critérios. Àquela época podiam ser arrolados trinta diferentes conjuntos de critérios, oriundos de vários grupos de especialistas dos Estados Unidos e da Europa. O neurologista concluía afirmando que um diagnóstico de "morte de todo o encéfalo" (whole-brain death) ${ }^{3}$, com o qual se esgotariam as possibilidades de sobrevivência, poderia ser considerado mais confiável do que aqueles apontados até então. Ao lado disso, crescia a legislação que acatava crenças médicas e populares. A preocupação com diagnósticos precipitados ou inadequados demandava com urgência critérios uniformes para atender também a condições éticas.

No intuito de fazer convergirem os múltiplos critérios e normatizar um conceito definitivo de morte cerebral, após debates extensos reuniram-se os gestores que formavam a President's Comission e em 1980 aprovaram o UDDA. O documento recomendava a definição de whole-brain death como referência para legislação em todos os estados norteamericanos. O UDDA foi imediatamente apoiado pela American Medical Association e pela American Bar Association e, em 1981, passou a vigorar nas leis da maioria dos estados norte-americanos; subseqüentemente o Canadá, através de uma reforma legislativa, publicou critérios nele baseados, vinculando-os a estatutos federais. O documento foi dividido em três curtas seções e uma nota introdutória de duas páginas. O preâmbulo delega a profissionais de medicina a deliberação de critérios para definição de morte. Figura também nessa introdução a necessidade de se distinguirem os quadros de whole-brain death, higher brain death e estado vegetativo persistente (persistent vegetative state). O primeiro parágrafo marca a divisão que passa a vigorar entre duas mortes clinicamente aceitáveis: (1) a parada irreversível das funções respiratórias e circulatórias; e (2) a parada irreversível de todas as funções do cérebro inteiro, incluindo o tronco encefálico. Nessas circunstâncias, o 'indivíduo' está morto. O segundo parágrafo apóia os dois tipos de morte com referência para o campo jurídico. Por fim, o terceiro parágrafo sugere o título do documento, que deve, a partir de então, ser referido como o Uniform Determination of Death Act (President's Comission..., Nov. 1981). 
Intermediário entre o relatório do Ad Hoc Committee e o UDDA foi o Uniform Anatomical Gift Act, documento estatutário cuja cópia foi publicada no Jama em 1968, poucos meses após a definição de morte cerebral. A intenção desse documento era criar parâmetros para a livre doação de órgãos, 'presentes anatômicos' a serem cedidos voluntariamente. Nele já estão incluídas a necessidade de declaração de morte cerebral e a administração dos órgãos por equipes médicas distintas. Estavam portanto estabelecidas ali as bases para a doação consentida.

Os três documentos mencionados evidenciam a inequívoca vinculação entre redefinição da morte e transplante de órgãos, mas nenhum deles recupera a descrição de coma dépassé, antecessora da definição de morte cerebral. De fato, precedendo o esforço norte-americano de redefinição da morte diante de pacientes em estado de inconsciência ligados a respiradores artificiais, os neurologistas franceses Jouvet (1959) e Mollaret e Goulon (1959) haviam descrito, nos anos 50, esse novo tipo de coma. A descrição dos franceses é freqüentemente mencionada como a primeira conceituação do que viria a ser denominado morte cerebral, a qual anuviou a expressão francesa.

Mollaret e Goulon (1959) basearam-se no estudo de 23 casos de pacientes em coma. O registro de eletroencefalograma (EEG) foi utilizado como evidência do estado comatoso. O EEG com traçado plano (tracé plat à $E E G$ ) foi apontado por eles como a base para a nova definição de coma:

Há três graus tradicionais de coma aos quais sugerimos o acréscimo de um quarto grau, o de coma dépassé: ressaltamos nós mesmos que essa expressão não é perfeitamente satisfatória e que aceitaremos todas as sugestões de alguma melhor. Mas é a expressão utilizada depois de quatro anos de trabalho, quando a definimos como: o coma no qual se sobrepõe a abolição total das funções da vida de relação não apenas das perturbações, mas de uma abolição igualmente total das funções da vida vegetativa (Mollaret, Goulon, 1959, p.4; grifos do original).

Os neurologistas franceses mostravam-se cientes de que esse tipo de coma e o trabalho das equipes de reanimação tendiam a "prolongar um espetáculo cada vez mais doloroso aos olhos dos familiares" (Mollaret, Goulon, 1959, p.4) e alertavam para a criação de critérios capazes de traçar uma fronteira precisa entre a vida e a morte. E apesar de terem apontado direções que seriam incorporadas aos estudos dos colegas norte-americanos, foram as colocações e os critérios destes últimos que serviram de parâmetros para a consolidação da nova definição de morte e dos critérios para seu diagnóstico. Com a análise das publicações mencionadas, pode-se observar que a comunidade médica dos Estados Unidos estava se preparando não só para a tarefa de garantir essa redefinição, mas também para assegurar que ela fosse reconhecida juridicamente.

Era notória a posição favorável de Henry Beecher $(1959,1966$, Spring 1969, 1969) à experimentação com seres humanos. O famoso anestesiologista foi um dos principais articuladores, tendo ocupado a posição de coordenador do grupo (Belkin, July 2003). Em suas articulações em Harvard, Beecher garantiu que importantes departamentos daquela Universidade - Medicina, Saúde Pública, Teologia e Direito - integrassem o comitê. Ao compor o Ad Hoc Committee e se projetar como um dos debatedores mais ferrenhos em prol de uma nova definição de morte, Beecher (1968) evidencia, sem embaraço, sua convicção de que "o momento da morte pode ter importância legal, mas os critérios pelos 
quais a morte é estabelecida dependem de evidência médica" (p.1425). Ao mesmo tempo, interroga e oferece resposta para a principal questão levantada na primeira onda do debate sobre morte cerebral, logo após a publicação do relatório do comitê que liderava.

Qual é o momento da morte e quais são seus critérios? Muitos hoje em dia sustentam a visão de que quando a consciência está permanentemente perdida, quando se ultrapassa o ponto de não-retorno em casos de lesão cerebral para os quais não há esperança, este é o 'momento' da morte. E seus critérios são a parada da atividade elétrica no cérebro após um período prolongado ..., e a absoluta falha em responder a qualquer estimulação intensa (Beecher, 1968, p.1427).

Aproximadamente um ano após a publicação do relatório do Ad Hoc Committee, Beecher (Nov. 1969) avaliou o impacto da nova definição e concluiu que "a aceitação do coma irreversível, 'morte cerebral', como morte de fato não é uma mera questão acadêmica, mas algo que acarreta enormes conseqüências em termos das mudanças na filosofia e prática médicas" (p.1071).

Em suas publicações sobre a morte cerebral Beecher se apresenta como porta-voz daqueles que defendem ser a morte cerebral um campo exclusivo de médicos, ainda que admitisse certa tolerância à inclusão de outros campos de saber, convocados no primeiro momento do debate sobre o tema. O reconhecimento de que as posições da teologia, da filosofia e do direito eram importantes restringia-se à possibilidade de enriquecimento do debate, mas o anestesiologista sempre reservou à ciência médica lugar de destaque na identificação da morte cerebral, equiparando-a à morte do indivíduo. Apesar dessa aparente abertura de Beecher para o diálogo com outras áreas de conhecimento e com a sociedade, Pernick (1999) enfatiza que, na composição do Ad Hoc Committee, Beecher insistia em afirmar que os critérios de morte cerebral "eram exclusivamente do domínio da profissão médica" (p.20). A conseqüência direta desse posicionamento, abraçado por outros atores de projeção que contribuíram para o debate, é a hegemonia de descrições médicas na regulamentação da morte cerebral nos Estados Unidos e em outros países.

Outro importante ator nesse cenário foi o teólogo cristão Paul Ramsey, crítico contumaz do processo de redefinição da morte e das estratégias do Ad Hoc Committe e seu relatório. Ramsey foi um dos fundadores de um dos espaços mais importantes de discussão sobre a redefinição da morte, a Task Force on Death and Dying, do Hastings Center, em que ele e Beecher travaram intensos debates (Rado, Winter 1987; Belkin, July 2003). Patient as a person, livro publicado por Ramsey em 1970, teve ampla repercussão entre os interessados nos caminhos éticos da medicina daquele período, quando questões de vida e de morte estavam sendo levantadas. Nessa obra, ele chama a atenção para as ambigüidades do relatório de 1968 que, afirma, negligenciou questões éticas importantes. Destaca a necessidade de definir a morte do ser humano, se ela se refere apenas à morte do cérebro, e se questões religiosas deveriam participar dessa definição. Também discute o recurso a meios extraordinários em detrimento de meios ordinários no 'dever' médico de salvar vidas, apontando que a abundante utilização dos primeiros gerava, na verdade, novos problemas éticos como a eutanásia e o prolongamento do morrer. Outro ponto enfatizado é a forte conexão entre a definição de morte cerebral e o transplante de órgãos. Ramsey (1970) pondera que o ponto crucial ao qual se havia chegado, na tecnologia de transplante de 
órgãos, qual seja, o transplante cardíaco, curiosamente havia apressado a redefinição da morte. O coração, outrora representado como sede da vida e da alma, havia sido profanado; a vida, ela mesma, havia sido tocada. O teólogo aponta: "porque o coração é um órgão singular que 'pulsa', é compreensível que se levantem sérias questões humanas - questões sobre o significado da vida e da morte - quando o coração é transplantado" (p.62). Sobre os transplantes conclui que, se fosse para colocar a definição de morte a serviço deles, ela não deveria ser revista: "Se a morte de ninguém deve por esse motivo [transplante] ser antecipada, então a definição de morte por esse motivo não deveria ser revista, nem os procedimentos para declarar que um homem está morto deveriam ser revisados para garantir acesso mais fácil a órgãos" (p.103; grifos do orignal).

A discussão proposta por Ramsey acabou contribuindo para a formulação de critérios no diagnóstico de morte cerebral. Sob o pretexto de conduzir o processo de doação de órgãos de maneira eticamente aceitável, promoveu-se a distinção do médico que assiste o paciente com morte cerebral, o doador, daqueles responsáveis pela condução dos testes necessários à confirmação da morte cerebral e, principalmente, da equipe responsável pelo outro paciente, o receptor. Essa delimitação entre as equipes médicas responsáveis pelo doador, pelos testes de confirmação e pelo receptor constitui até os tempos atuais a norma para a coleta de órgãos em diversos países, entre eles o Brasil.

Outros autores podem ser destacados nos debates sobre a redefinição da morte: Daniel Callahan (July 1971), presidente do Hasting Center e que, com Robert Veatch (1976), defenderia durante os anos 90 a definição de higher-brain death e outras questões éticas pertinentes; Robert Morison (1971) e Leon Kass (1971), que expressaram suas posições, o primeiro favorável à definição da morte como um processo, e o segundo sustentando que a morte é um evento. Os argumentos construídos nos primeiros anos de debate são aglutinados em diferentes teses sobre a morte cerebral, detalhadas adiante. No centro das preocupações da bioética nascente encontra-se a demarcação do que há de 'humanidade' no ser humano. Quem morre seria a questão principal, ponderou Morison (1971), que argumentou ainda ser impróprio equivaler a morte de uma pessoa à morte de um de seus órgãos.

\section{Do coração ao cérebro}

Cantado em verso e prosa como a sede das emoções humanas, o coração perdeu, nos anos 60, sua condição de órgão privilegiado para se afirmar a morte de alguém. Ganhou contudo status de órgão nobre para a tecnologia de transplantes.

Vimos que a história do transplante cardíaco está intricada na definição de morte cerebral. Um momento crucial: 3 de dezembro de 1967, quando foi realizado o primeiro transplante de coração em seres humanos, na Cidade do Cabo, África do Sul. Antes mesmo de haver uma declaração oficial acerca da definição de morte cerebral, o primeiro coração humano passou pelas mãos de Christiaan Barnard, no caminho entre o corpo de uma jovem doadora e um senhor que recebeu o órgão. Barnard havia estudado com Shumway, persistente cirurgião da Universidade de Stanford, que ali conduzia experimentos de transplante cardíaco com animais. Num artigo em que reporta duas cirurgias com seres humanos, Barnard (Oct. 
1968) opina que é prematura a objeção a transplantes cardíacos em seres humanos. Seu relato foi publicado cinco meses antes do relatório do Ad Hoc Committe.

A façanha de Barnard teve estrondosa repercussão na mídia, sendo amplamente divulgada e transformando o cirurgião em garoto-propaganda da campanha dos transplantes de órgãos (Stevens, Winter 1995; Hoffenberg, Dec. 2001; Lock, 2002). Considerar o transplante cardíaco uma ação condenável ou não foi uma questão que refletiu o clima de espanto e terror com que a façanha foi recebida pelo público. A redefinição da morte ainda estava por se fazer; portanto havia a dúvida se o ato de retirar um coração ainda pulsante de um paciente para acomodá-lo em outra pessoa era algo louvável.

Raymond Hoffenberg (Dec. 2001), uma das testemunhas dos dois primeiros transplantes de coração realizados na Cidade do Cabo, relata que o segundo paciente transplantado pela equipe de Barnard viveu mais 18 meses, tendo sobrevida regrada. Hoffenberg tinha sob sua assistência o segundo doador requisitado pela equipe de Barnard. À pergunta "por que a Cidade do Cabo foi palco do primeiro transplante de órgão em humano?", o cirurgião responde afirmando que a África do Sul cultivava o desrespeito pela vida humana, acentuado pelo clima político entre negros e brancos naquele país.

O transplante cardíaco foi recebido como um 'presente dos deuses', um milagre moderno aclamado em número especial da revista South African Medical Journal (SAMJ, dez. 1967). Recursos humanos e tecnológicos não faltavam aos Estados Unidos para realização do primeiro transplante cardíaco em seres humanos àquela época. A equipe de Norman Shumway formou a primeira geração de cirurgiões que realizaria o transplante ao redor do mundo. Para Hoffenberg (Dec. 2001), o que inibiu os cirurgiões estadunidenses diz respeito aos entraves legais e às discussões éticas mais do que à falta de habilidade técnica para a realização do primeiro transplante. A análise de Hoffenberg é corroborada por Lock (2002), que reconhece a fraca preocupação com aspectos éticos que vigorava na África do Sul àquela época, em contraste com os debates nos Estados Unidos e na Grã-Bretanha sobre o tema.

Vinte anos após o feito pioneiro de Barnard, o Texas Heart Institute Journal publicou editorial especial narrando as duas décadas de transplante cardíaco. Assinado por Cooley (Sep. 1987), um dos expoentes do transplante cardíaco nos Estados Unidos, anunciava-se orgulhosamente que "a era dos transplantes despontou no dia 3 de dezembro de 1967, quando Chistiaan Barnard eletrizou o mundo ao remover o coração de um ser humano e implantá-lo em outro ser humano" (p.225). Em 1968, ano da publicação do relatório do Ad Hoc Committee, um ano após o episódio da Cidade do Cabo, 107 transplantes cardíacos foram realizados por 64 diferentes equipes em 24 países, nos informa Cooley, que chefiou uma dessas equipes e relatou sua experiência no Jama (Cooley et al., Aug. 1968).

Apesar dos feitos saudados como gloriosos, a 'era do transplante cardíaco' só encontrou sustentação com a descoberta do efeito imunossupressor da ciclosporina, que só na década de 1980 foi incorporada à prática de transplantes para evitar a rejeição de tecidos transplantados (Cooley, Sep. 1987; DiBardino, 1999). Até então, o campo do transplante cardíaco era altamente experimental, contando com os feitos heróicos nos anos imediatamente posteriores a 1967 e a persistência de poucos grupos que se atreviam a desenvolver a técnica e a lidar com altas taxas de rejeição dos órgãos transplantados. Os relatos dos cirurgiões pareciam otimistas, ao afirmar que a sobrevida, ainda que média, era 
um avanço sem precedente para a história da cirurgia cardíaca (Cooley, Aug. 1968; Shumway, $1969,1971)$. No entanto a década posterior aos primeiros transplantes cardíacos foi marcada por altos custos financeiros e humanos (DiBardino, 1999).

O transplante cardíaco intensificou a exigência de nova definição de morte. Até a década de 1960, para todos os efeitos, a morte era evidenciada pela parada cardiorrespiratória do paciente. A pressão por uma definição de morte que permitisse a coleta do coração para transplante era realidade antes mesmo que a expressão morte cerebral fosse cunhada. Morte de quem? Mas morte de quê? Os 'pacientes sem esperança', alvo de discussões nos anos 50, transformaram-se em esperança de muitos na nova ordem do transplante cardíaco: morte de uns como promessa de vida para outros. Os pacientes conectados a respiradores artificiais, em estado irreversível de perda da consciência, ganharam uma nova denominação: pacientes com morte cerebral (brain dead patients). Construiu-se uma campanha pela associação do sujeito a sua consciência, a qual, por sua vez, deveria ser localizada no cérebro. A ausência de consciência, a 'morte do cérebro', seria condição suficiente para se declarar a morte do sujeito.

O debate sobre morte cerebral que se estabeleceu após o primeiro transplante cardíaco foi guiado, num primeiro momento, pela necessidade, por parte da comunidade médica, de proteger-se dos medos e da ignorância do público com relação aos transplantes. Contudo a partir dos anos 70 a discussão voltou-se para a proteção do público contra os potenciais prejuízos das práticas de transplantes. A morte cerebral era então retratada na mídia como a expropriação do direito à morte digna do paciente, para quem os "medos de se ser equivocadamente declarado morto por médicos precipitados, descuidados ou membros de equipes de transplante de órgãos ainda permaneceram importante barreira para a ampla aceitação pública tanto da doação de órgãos quanto da morte cerebral" (Pernick, 1999, p.18). A desconfiança da opinião pública quanto aos avanços médicos não barrou o fortalecimento das tecnologias, rapidamente incorporadas à prática médica cotidiana. Paralelamente à transformação dos transplantes em rotina médica, as teses sobre morte cerebral foram delimitadas, vencendo barreiras jurídicas e políticas pela exaustiva repetição de seus pressupostos.

\section{Críticas culturais à definição de morte cerebral}

As incisivas transformações na definição de morte que ocorreram no debate entre médicos, advogados, políticos e filósofos em meados do século XX, como vimos, não se restringiram às dimensões acadêmica e política. Apesar de ter sido apresentada, em muitos momentos, como matéria exclusiva da medicina ou da emergente bioética, a morte cerebral era dada a conhecer ao público leigo à medida que se consolidava, especialmente por estar vinculada à divulgação das tecnologias de transplante de órgãos.

A relação na qual se dá a interlocução do fato médico com a sociedade como um todo é discutida em estudos desenvolvidos no campo das ciências humanas, que questionam a propagação da definição de morte cerebral e contribuem para a desmontagem da morte cerebral como caixa-preta produzida pelo saber biomédico. A partir dos anos 80, a antropologia e a sociologia médica apresentam investigações críticas sobre o debate 
desencadeado no âmbito da bioética a respeito de temas fronteiriços entre vida e morte (Hogle, 1999; Crowley-Matoka, Lock, 2006; Sharp, 2006). Sobressaem os trabalhos de etnografia desenvolvidos por antropólogas, em que outras culturas são comparadas com a norte-americana no que diz respeito à morte cerebral, como os de Margaret Lock e Linda Hogle. Também merece destaque o trabalho de Leslie Sharp, seguindo o caminho da crítica à implantação de tecnologias de transplante como prática rotineira no contexto estadunidense e da análise sobre os paradoxos gerados na consolidação desses procedimentos. Nessas investigações acentua-se a aceitação pública da definição de morte cerebral, em diferentes contextos culturais.

Leslie Sharp $(1995,2006)$, antropóloga americana, aborda a cultura de seu país ao explorar o que concebe como "ideologização dos transplantes". Aponta a biomedicina como um sistema de pensamento dominante nos Estados Unidos, sendo "indubitavelmente experimental, invasiva e tecnocrática" (Sharp, 2006, p.30). Os transplantes se traduzem como mero exemplo altamente sofisticado desse sistema de pensamento. Em Strange harvest, publicado em 2006, destaca como um eixo de análise a "ideologia especializada sobre transplantes", presente nos Estados Unidos. A ideologização dos transplantes é construída em decorrência da pressão constante sobre a United Network for Organ Sharing (Unos) pela manutenção da credibilidade dos procedimentos relacionados aos transplantes. Assim, uma das tarefas da agência responsável pela captação de órgãos é incentivar o 'altruísmo abnegado' (selfless altruism) da população, convocando-a a aderir a campanhas de doação. Sharp (2006) desvela os jogos de palavra, eufemismos e metáforas que transformam o ato de doar ou receber um órgão num gesto de generosidade e desprendimento. Expressões atenuadoras de aspectos obscuros dos transplantes são correntemente utilizadas no contexto estadunidense, tais como: o órgão é um 'presente de vida' (gift of life); ele não é retirado, mas colhido (harvest); ele não é comprado e sim obtido (procured). Evita-se assim o raciocínio biomédico de que o corpo humano é composto por partes reutilizáveis e intercambiáveis. A autora dedicou-se, em seus estudos, a desvelar a ambigüidade inerente à terminologia de profissionais que discutem a morte cerebral e os transplantes, desconectando significados produzidos pelos discursos especializados sobre o assunto.

Referência internacional na desmontagem da definição de morte cerebral é Margaret Lock. Assim como os trabalhos de Sharp, o método etnográfico orientou as pesquisas de Lock. Além do notório Twice dead, publicado em 2002, Margaret Lock apresenta vasta produção em que aborda a recepção da definição estadunidense de morte cerebral pela cultura japonesa. A morte cerebral, no Japão, não foi acolhida como o fim da vida da pessoa, uma vez que naquele país a morte é compreendida como um 'processo natural', explica Lock (1997a). E ressalta que a fronteira entre natural e social naquela cultura, notadamente no que diz respeito à morte, "nunca foram rigidamente definidas, pois os ancestrais são imortalizados como seres que continuam a atuar no mundo cotidiano" (p.134).

Lock (1997b) também observa que a primeira definição de morte cerebral foi anunciada em 1974 pela Japan Electroencephaly Association, contudo sem correlação com o fim da vida de uma pessoa. A finalidade da expressão era preparar familiares para a morte iminente de seu parente. Somente em 1988 a Associação Médica Japonesa, após compor um grupo de trabalho para discutir a morte cerebral, aceitou-a como a extinção da vida humana. A 
decisão provocou oposição entre pares, da opinião pública e do Patients' Rights Committee. Um fórum governamental, Special Cabinet Committee on Brain Death and Organ Transplantation, foi designado para discutir o assunto e buscar uma posição que conciliasse interesses dos agentes e das instituições envolvidas. Entre 1989 e 1992 esse fórum deu segurança ao governo japonês para se manifestar, "pronto para sustentar um movimento em direção à legalização da morte cerebral como o término da vida" (p.226). Tal posicionamento oficial do governo foi contestado pela Japan Federation of Bar Associations, apoiado por associações de pacientes, opinião pública e segmentos médicos. Argumentos centrais, nos movimentos de oposição à nova definição de morte, era a falta de confiança no diagnóstico médico e as práticas elitistas dos profissionais da área.

Em Twice dead Lock (2002) reúne resultados de anos de pesquisa etnográfica sobre morte cerebral nos Estados Unidos, no Canadá e no Japão. No preâmbulo do famoso livro, questiona: "se o conceito de 'pessoa' é disseminado em todo o corpo, ou até mesmo se estende para fora do corpo, então a destruição do cérebro não é facilmente reconhecida como significado de morte" (p.8). A marcada diferença entre o Japão e a América do Norte, para a antropóloga, está na não-aceitação, no primeiro, da autoridade médica como elemento único para decidir o que é a morte e quando ela acontece. O repúdio à naturalização médica do morrer é patente na cultura japonesa, o que ocorre de maneira diferente no contexto alemão, como veremos a seguir.

Linda Hogle (1999) desenvolveu pesquisas em antropologia médica no cenário alemão, voltados para a experimentação com seres humanos e ao transplantes de órgãos. A antropóloga aproximou-se da "medicina onde ela acontece", envolvendo gestores das tecnologias de transplantes na Alemanha, médicos e não-médicos, cirurgiões, enfermeiras, patologistas. Além de entrevistas formais, a autora observou sessões de discussão política sobre os transplantes de órgãos e incorporou a seus dados debates veiculados pela mídia alemã, em encontros sociais e em agremiações e conversas acadêmicas.

Uma das características mais marcantes do contexto analisado por Hogle (1999) é a aversão da população alemã pelo caráter experimental dos transplantes de órgãos. A associação inevitável com as práticas médicas no Terceiro Reich direciona o debate bioético sobre transplantes naquele país. Matérias na mídia, analisadas pela antropóloga, revelam a ansiedade moral instaurada com a redefinição da morte. A autora avalia que a política do Partido Nacional Socialista justifica parte dessa ansiedade, uma vez que seus princípios permitiam que alguns seres humanos fossem considerados "imprestáveis demais para participar de uma sociedade alemã superior, embora fossem bastante valiosos na economia da ciência a serviço de Estado" (p.45). A redefinição de morte cerebral no país só foi possível com amplo debate entre médicos, juristas e filósofos, organizados em comissões acadêmicas e políticas, à semelhança do que ocorreu nos Estados Unidos e no Japão, mas por razões distintas.

Os estudos antropológicos nos ajudam a esboçar o cenário brasileiro de discussão - ou ausência de discussão - sobre a morte cerebral. Sem defender a mera reprodução das investigações destacadas anteriormente, acredito que elas podem sinalizar caminhos para futuras investigações da mesma natureza, quanto ao nosso país. 
No Brasil, a definição de morte cerebral foi exigida por ocasião do primeiro transplante cardíaco entre humanos, realizado em 26 de maio de 1968 pelo cirurgião Euryclides Jesus Zerbini. O receptor, o boiadeiro João Ferreira da Cunha, ganhou o órgão retirado de Luís Ferreira Barros, vítima de acidente de trânsito. João Ferreira da Cunha sobreviveu ao transplante por pouco menos de um mês. Na ocasião, a pedido da equipe de Zerbini, "foi estabelecido no Hospital das Clínicas da FMUSP o conceito e comprovação da morte real, calcado somente em critérios eletroencefalográficos" (Santos, 1998, p.30).

Na década de 1950 Zerbini liderava uma das equipes de cardiologia de maior destaque no Brasil, reconhecida por seu pioneirismo no campo da cirurgia cardiovascular. Costa (1998) avalia que o impacto da façanha de Zerbini, a despeito do ufanismo que a sucedeu, beneficiou os serviços de cirurgia cardíaca de todo o país, ao conferir prestígio e reconhecimento social a essa especialidade.

Aparentemente houve no Brasil uma rápida incorporação dos transplantes aos procedimentos médicos de rotina. Não se encontraram publicações que mencionassem opiniões contrárias à definição de morte cerebral. Em vez disso, a expertise médica é enfatizada no que concerne à institucionalização dos transplantes no país. Ainda assim, os transplantes de órgãos de pacientes com morte cerebral só se tornaram rotina médica nos anos que se seguiram ao uso de imunossupressores no combate à rejeição. A regulamentação dos transplantes foi feita prontamente, através da lei 5.479 de 10 de agosto de 1968 (Brasil, 10 ago. 1968), que não menciona a expressão 'morte encefálica' ou 'morte cerebral', restringindo-se a estabelecer que a retirada de partes do corpo para fins terapêuticos "deverá ser precedida da prova incontestável da morte" (art. 2) e "somente poderão ser realizados por médico de capacidade técnica comprovada" (art. 4).

Da literatura pesquisada, fica evidente que a definição de morte cerebral ligada à competência médica não foi questionada. A legitimação jurídica da definição se apresenta como complementar ao saber médico, não necessariamente a ele se opondo ou rivalizando. O diálogo entre medicina e direito no Brasil parece, portanto, mais cordial, visando ao estabelecimento de um 'paradigma médico-forense' para a definição da morte cerebral (Santos, 1998) ou a ajustes na legislação que a reconhece como suficiente para a retirada de órgãos (Sá, 2003).

Apresentada como consenso médico, a 'morte encefálica' não só naturaliza a experiência da morte como também inibe a discussão sobre as dimensões subjetivas, culturais e sociais da morte. A tradução de brain death nos documentos oficiais brasileiros como 'morte encefálica' sugere que tal definição, de cunho aparentemente mais técnico, diz respeito apenas aos especialistas. Um efeito disso é que o debate ético em torno da definição de morte cerebral aparece de forma incipiente no cenário nacional.

Nos Estados Unidos e em outros países, a formação de comissões de especialistas de campos diversos do conhecimento e leigos para discutir a morte cerebral foi uma das formas de expressar oposição à hegemonia médica nas decisões sobre o assunto. Ao contrário disso, no Brasil a soberania da medicina na decisão sobre o que é a morte não foi colocada em questão. Para transitar com segurança nessas afirmações, seria preciso desenvolver investigação mais aprofundada sobre a difusão da morte cerebral e os transplantes de órgãos no Brasil. De qualquer maneira, é surpreendente a aparente resignação do meio 
acadêmico e da sociedade em geral ante o saber médico sobre morte cerebral, comparada ao efervescente debate internacional sobre o tema.

\section{Considerações finais}

Rompendo gradativamente com o ideal de melhorar a vida da humanidade, a prática médica engajou-se em recriar novas formas de morrer e de sobreviver. Com suas práticas modificadas, a ciência médica incumbiu-se de inventar novos conhecimentos sobre elas, tanto para sustentá-las quanto para enfrentar o debate em torno delas.

Em nada conciliável com os avanços da tecnologia médica, a correlação da alma humana com o coração sofreu golpe decisivo com o transplante de coração em seres humanos. Uma nova sede para o ser humano, mais moderna e coerente, o cérebro, pretendendo-se solidamente construída com evidências como o EEG e a definição de morte cerebral, consolidou-se da década de 1960 em diante.

As análises aqui desenvolvidas sustentam a afirmação inicial deste artigo, de que a maquinaria de suporte de vida e as novas práticas e procedimentos médicos antecederam a produção de argumentos em prol da construção da definição de morte cerebral. Máquinas e argumentos, nessa ordem, foram necessários para a consolidação da morte cerebral como fato médico. A remontagem dos argumentos construídos para sustentar tal fato, desenvolvida principalmente em estudos antropológicos, permite o desvelamento dos embates travados em torno do tema.

O mergulho na literatura científica sobre a morte cerebral permitiu evidenciar conexões e rupturas entre vozes coletivas, ora dissonantes, ora convergentes. Ao longo do século $\mathrm{XX}$, médicos, juristas, filósofos, teólogos e antropólogos teceram uma imbricada rede de idéias e estilos de pensamento coletivo, que se tentou evidenciar ao longo deste trabalho. Parte desse coletivo conquistou, para a definição de morte cerebral, o status de fato médicocientífico. Outra parte exprimiu seu posicionamento contrário à redefinição da morte. Muitos matizes entre esses pontos da trama de artigos de periódicos, relatórios, coletâneas, edições especiais de periódicos, livros e capítulos de livros insinuam que esse não é um debate que promova consenso.

\section{NOTAS}

* A discussão apresentada neste artigo é parte da pesquisa sobre a história da definição de morte cerebral realizada no meu doutorado em Saúde Coletiva (IMS/UERJ), com apoio da Capes.

${ }^{1}$ Nesta e nas demais citações de textos em outros idiomas a tradução é livre.

${ }^{2}$ Adoto deliberadamente a expressão 'morte cerebral' em vez de 'morte encefálica' para evitar a terminologia médica e marcar a discussão que pretendo fazer a partir das ciências humanas. Sempre que a expressão 'morte encefálica' aparecer no corpo do texto, ela será destacada por sua vinculação com o discurso biomédico.

${ }^{3}$ Há três principais derivações da definição de morte cerebral: whole-brain death, brain stem death e higher brain death. As expressões em inglês serão mantidas por não haver consenso nas suas traduções para o português, como também pelo fato de essas derivações estarem fortemente vinculadas a características anatômicas, cujos meandros não serão contemplados neste artigo. 


\section{REFERÊNCIAS}

AD HOC COMMITTEE..

Ad Hoc Committee of the Harvard Medical School to Examine the Definition of Brain Death. A definition of irreversible coma. Journal of the American Medical Association, Chicago, v.205, n.6, p.337-340. Aug. 1968.

ANÔNIMO.

A way of dying. The Atlantic Monthly, Boston, p.53-55. Jan. 1957.

AYD, Frank Joseph.

The Hopeless Case. Journal of the American Medical Association, Chicago, v.181, n.13, p.1099-1102. 1962.

BARNARD, Chritiaan Neethling.

Human cardiac transplantation: an evaluation of the first two operations performed at the Groote Schuur Hospital, Cape Town. The American Journal of Cardiology, New York, v.22, p.584-596. Oct. 1968.

BEECHER, Henry Knowles.

After de "Definition of Irreversible Coma". The New England Journal of Medicine, Boston, v.281, n.19, p.1070-1071. Nov. 1969.

BEECHER, Henry Knowles.

Scarce resources and medical advancement. Daedalus: Journal of the American Academy of Arts and Sciences, Cambridge, v.98, n.2, p.275-313. Spring 1969.

BEECHER, Henry Knowles.

Human studies. Science, Washington, v.164, n.3885, p.1256-1258. 1969.

BEECHER, Henry Knowles.

Ethical problems created by hopelessly unconscious patient. New England Medical Journal, Boston, v.278, n.26, p.1425-1430. 1968.

BEECHER, Henry Knowles.

Ethics. New England Medical Journal, Boston, v.274, n.24, p.1354-1359. 1966.

BEECHER, Henry Knowles.

Experimentation in man. Springfield: Charles C. Thomas Publisher. 1959

BELKIN, Gary S.

Brain death and the historical understanding of bioethics. Journal of the History of Medicine, Oxford, v.58, p.325-361. July 2003.

BENDIXEN, Henrik H.; KINNEY, John M. History of intesive care. In: Kinney, John M. (Ed.). Manual of surgical intensive care. Philadelphia: Saunders. p.3-14. 1977.

BLACK, Peter.

Brain death. New England Journal or Medicine, Boston, v.299, p.338-344. 1978.
BRASIL.

Lei 5.479. Dispõe sobre a retirada e transplante de tecidos, órgãos e partes de cadáver para finalidade terapêutica e científica. Disponível em: <http://www6.senado.gov.br/sicon/ ExecutaPesquisaAvancada.action $>$. Acesso em: 10 out. 2007. 10 ago. 1968.

CALLAHAN, Daniel.

Profile: Institute of Society, Ethics and the Life Sciences. BioScience, Washington, v.21, n.13, 735-737. July 1971.

COOLEY, Denton Arthur.

Cardiac transplantation: the first twenty years and beyond. Texas Heart Institute Journal, Houston, v.14, n.3, p.225-229. Sep. 1987.

COOLEY, Denton Arthur et al.

Transplantation of the human heart: report of four cases. Journal of the American Medical Association, Chicago, v.205, n.7, p.479-486. Aug. 1968.

COSTA, Iseu Affonso da.

História da cirurgia cardíaca brasileira. Revista Brasileira de Cirurgia Cardiovascular, São Paulo, v.13, n.1, p.1-7. 1998.

CROWLEY-MATOKA, Megan; LOCK, Margaret. Organ transplantation in a globalised world. Morality, London, v.11, n.2, p.166-181. 2006.

\section{DAEDALUS.}

Daedalus: Journal of the American Academy of Arts and Sciences. Cambridge, v.98, n.2. Spring 1969.

DIBARDINO, Daniel J.

The history and development of cardiac transplantation. Texas Heart Institute Journal, Houston, v.26, n.3, p.198-205. 1999.

DRINKER, Paul; SHAW, Louis Agassiz. The prolonged administration of artificial respiration. Journal of The Franklin Institute, Philadelphia, v.213, n.4, p.355-372. 1932.

FARRELL, John J.

The right of a patient to die. The Journal of the South Carolina Medical Association, Greenville, v.54, n.7, p.231-233. 1958.

FLECK, Ludwik.

Genesis and development of a scientific fact.

Chicago: The University of Chicago Press. 1.ed., 1935. 1979.

HILBERMAN, Mark.

The evolution of intensive care units. Critical Care Medicine, New York, v.3, n.4, p.159-165. 1975. 
HOFFENBERG, Raymond.

Christiaan Barnard: his first transplants and their impact on concepts of death. British Medical Journal, London, v.323, p.1478-1480. Dec. 2001.

HOGLE, Linda.

Recovering nation's body: cultural memory, medicine and the politics of redemption. New Brunswick: Rutgers University Press. 1999.

HOWELL, Joel D.

Technology in the hospital: transforming patient care in the early twentieth century. Baltimore: Johns Hopkins University Press. 1995.

IBSEN, Bjorn Aage.

From anaesthesia to anaesthesiology: personal experiences in Copenhagen during the past 25 years. Acta Anaesthesiologica Scandinavica Supplementum, Copenhagen, n.61, p.1-69. 1975.

JONAS, Hans.

Philosophical reflections on experimenting with human subjects. Daedalus: Journal of the American Academy of Arts and Sciences, Cambridge, v.98, n.2, p.219-247. Spring 1969.

JOUVET, Michel.

Diagnostic electro-sous-cortico-graphique de la mort du système nerveux central au cours de certains comas. Electroencephalography and Clinical Neurophysiology, Amsterdam, v.11, p.805-808. 1959.

KASS, Leon R.

Death as an event: a commentary on Robert Morison. Science, Washington D.C., v.173, n.3998, p.698-702. 1971.

KATZ, Samuel L.

Conquering polio: from culture to vaccine Salk and Sabin. New England Journal of Medicine, Boston, v.351, n.15, p.1485-1487. 2004.

LAFORET, Eugene G.

The 'hopeless' case. Archives of Internal Medicine, Chicago, v.112, p.68-80. Sep. 1963.

LASSEN, Henry Cai Alexander.

Management of life-threatening poliomyelitis, Copenhagen 1952-1956. Edinburgh: E. \& S. Livingstone. 1956.

\section{LATOUR, Bruno.}

Ciência em ação: como seguir cientistas e engenheiros sociedade afora. São Paulo: Ed. Unifesp. 2000.

LOCK, Margaret.

Twice dead: organ transplants and the reinvention of death. Berkeley: University of California Press. 2002.
LOCK, Margaret.

The unnatural as ideology: contesting brain death in Japan. In: Asquith, Pamela J.; Kalland, Arne (Ed.). Japanese images of nature: cultural perspectives. Richmond: Curzon Press. p.121-144. 1997a.

LOCK, Margaret.

Displacing suffering: the reconstruction of death in North America and Japan. In: Kleinman, Arthur; Das, Veena; Lock, Margaret (Eds.). Social suffering. Berkeley: University of California Press. p.208-244. 1997b.

MAXWELL, James $\mathrm{H}$.

The iron lung: halfway technology or necessary step? The Milbank Quarterly, New York, v.64, n.1, p.3-29. 1986.

MOLLARET, Pierre; GOULON, Maurice. Le coma dépassé. Revue Neurologique, Paris, v.101, n.4, p.3-15. 1959.

MORISON, Robert R.

Death: process or event? Science, Whashington D.C., v.173, n.3998, p.694-698. 1971.

NATIONAL CONFERENCE...

National Conference of Commissioners on Uniform State Laws. Uniform Anatomical Gift Act. Journal of the American Medical Association, Chicago, v.206, n.11, p. 2505-2506. Dec. 1968.

PERNICK, Martin S.

Brain death in a cultural context: the reconstruction of death, 1967-1981. In: Youngner, Stuart J.; Arnold, Robert M.; Schapiro, Renie (Ed.). The definition of death: contemporary controversies. Baltimore: The Johns Hopkins University Press. p.3-33. 1999.

PIO XII, Papa.

Reanimatione [The prolongation of life]. Acta Apostolicae Sedis, Vaticano, p.1027-1033. 24 nov. 1957.

\section{PRESIDENT'S COMMISSION...}

President's Commission for the Study of Ethical Problems in Medicine and Biomedical and Behavioral Research. Uniform Definition of Death Act. Journal of the American Medical Association, Chicago, v.246, n.19, p.2184-2186. Nov. 1981.

\section{PRESIDENT'S COMMISSION...}

President's Commission for the Study of Ethical Problems in Medicine and Biomedical and Behavioral Research. Defining death: medical, legal, and ethical issues in the determination of death. Washigton D.C.: US Government Printing Office. 1981.

RADO, Leslie.

Cultural elites and the institutionalization of ideas. Sociological Forum, v.2, n.1, p.42-66. Winter 1987. 
RAMSEY, Paul.

The patient as person. New Haven: Yale University Press. 1970.

REID, Fred D.

Prolongation of life or prolonging the act of dying? Journal of the American Medical Association, Chicago, v.202, n.2, p.181. 1967.

SÁ, Maria de Fátima Freire de.

Biodireito e direito ao próprio corpo. 2. ed. Belo Horizonte: Del Rey. 2003.

SABIN, Albert Bruce.

Pathogenesis of poliomyelitis reappraisal in the light of new data. Science, Washington D.C., v.123, n.3209, p.1151-1157. 1956.

SALK, Jonas Edward.

Studies in human subjects on active immunization against poliomyelitis. Journal of the American Medical Association, Chicago, v.151, n.13, p.1081-1098. 1953.

SANTOS, Maria Celeste C. Leite. Morte encefálica e a lei de transplante de órgãos. São Paulo: Ed. Oliveira Mendes. 1998.

SHARP, Leslie A.

Organ transplantation as a transformative experience: anthropological insights into the restructuring of the self. Medical Anthropology Quarterly, Washington D.C., v.9, n.3, p.357-389. 1995.

SHARP, Leslie A.

Strange harvest: organ transplants, denatured bodies, and the transformed self. Berkeley: University of California Press. 2006.

SHUMWAY, Norman Edward.

Present status of heart transplantation in man. Proceedings of the American Philosophical Society, Washingon D.C., v.115, n.4, p.267-270. 1971.

SHUMWAY, Norman Edward.

Transplantation of an unpaired organ, the heart. Proceedings of the National Academy of Sciences of the United States of America, Washingon D.C., v.63, n.4, p.1032-1033. 1969.

SAMJ

South African Medical Journal. Cape Town, v.41, n.48. Dec. 1967.

STEVENS, Tina.

Redefining death in America, 1968. Caduceus, Springfield, p.207-219. Winter 1995.

THOMAS, Lewis.

The technology of medicine. New England Journal of Medicine, Boston, v.285, n.24, p.1366-1368. 1971.

VEATCH, Robert M.

Death, dying and the biological revolution: our last quest for responsibility. New Haven: Yale University Press. 1976.

VOVELLE, Michel.

La mort et l'Occident: de 1300 à nos jours. Paris: Gallimard. 1983.

WILLIAMSON, William P.

Prolongation of life or prolonging the act of dying? Journal of the American Medical

Association, Chicago, v.202, n.2, p.180-181. 1967.

WILLIAMSON, William P.

Life or death - whose decision? Journal of the American Medical Association, Chicago, v.197, n.10, p.139-141. 1966.

YOUNGNER, Stuart J.; ARNOLD, Robert M.; SCHAPIRO, Renie (Ed.)

The definition of death: contemporary controversies. Baltimore: Johns Hopkins University Press. 1999.

ZANER, Richard M.

Death beyond whole-brain criteria. Dordrecht: Kluwer Academic Publishers. 1988.

\section{$\rightarrow \rightarrow \rightarrow<<$}

